\title{
La rosuvastatina previene eventos cardiovasculares en personas con elevación de la proteina $C$ reactiva
}

\author{
Rosuvastatin prevents vascular events in people with elevated C-reactive protein
}

Ridker P. N Engl J Med. 2008; 359(21):2195-207.

\section{Objetivo}

Evaluar el beneficio del tratamiento con estatinas en altas dosis en pacientes con elevación de la proteína $C$ reactiva $(P C R)$ y colesterol dentro de límites normales.

\section{Diseño, lugar y pacientes}

Estudio aleatorizado, doble ciego, multicéntrico y controlado contra placebo, llevado a cabo en 1315 centros en 26 países de América, Europa, África y Asia del este.

Fueron aleatorizados a recibir $20 \mathrm{mg}$ de rosuvastatina o placebo, 17802 hombres y mujeres de 60 a 70 años de edad, con bajo y moderado riesgo cardiovascular (CV) colesterol LDL menor a $130 \mathrm{mg} / \mathrm{dL}$ y PCR de alta sensibilidad mayor a $2 \mathrm{mg} / \mathrm{L}$. Los pacientes fueron seguidos durante un máximo de cinco años con una mediana de seguimiento de 18 meses.

\section{Medición de resultados}

Se midió como objetivo principal la combinación de varios eventos: muerte cardiovascular, infarto de miocardio fatal y no fatal, accidente cerebrovascular (ACV) no fatal, necesidad de cirugía de revascularización miocárdica (CRM) o internación por angina inestable (Al); y como objetivo secundario, la aparición de cada uno de los anteriores en forma individual.

\section{Resultados}

El estudio fue detenido antes de tiempo debido a los resultados de un análisis preliminar. El grupo "rosuvastatina" presentó una reducción del LDL de $50 \%$ y de la PCR del $37 \%$. Hubo una reducción estadísticamente significativa tanto en el resultado combinado $\left(\mathrm{HR}^{*}\right.$ 0,56; IC95\% 0,46 a 0,69) como en cada uno de los eventos medidos en forma separada (ver tabla 1) sin diferencias en los efectos colaterales excepto una mayor incidencia de diabetes en el grupo "rosuvastatina".
Tabla 1: resultados comparativos entre los pacientes asignados aleatoriameente a rosuvastatina o placebo.

\begin{tabular}{|c|c|c|c|}
\hline Resultado & $\begin{array}{c}\text { Rosuvastatina } \\
\text { ( } \mathrm{n}=8901)\end{array}$ & $\begin{array}{l}\text { Placebo } \\
(n=8901)\end{array}$ & $\begin{array}{l}\text { Hazard Ratio } \\
\text { (IC del } 95 \% \text { ) }\end{array}$ \\
\hline Combinado $^{\mathrm{a}}$ & 142 & 251 & $0,56(0,46$ a 0,69$)$ \\
\hline IAM no fatal & 22 & 62 & $0,35(0,22$ a 0,58$)$ \\
\hline Alguna forma de IAM & 31 & 68 & $0,46(0,30$ a 0,70$)$ \\
\hline ACV no fatal & 30 & 58 & $0,52(0,34$ a 0,80$)$ \\
\hline Alguna forma de ACV & 33 & 64 & $0,52(0,34$ a 0,79$)$ \\
\hline Revascularización arterial & 71 & 131 & $0,54(0,41$ a 0,72$)$ \\
\hline Internación por angina inestable & 16 & 27 & $0,89(0,32$ a 1,1$)$ \\
\hline CRM o Internación por AI & 76 & 143 & $0,53(0,40$ a 0,70$)$ \\
\hline $\begin{array}{l}\text { IAM, ACV o muerte de origen } \\
\text { cardiovascular }\end{array}$ & 83 & 157 & $0,53(0,40$ a 0,69$)$ \\
\hline Muerte por cualquier causa & 198 & 247 & $0,80(0,67$ a 0,97$)$ \\
\hline
\end{tabular}

${ }^{\text {a }}$ Muerte cardiovascular, infarto agudo de miocardio (IAM) fatal y no fatal, accidente cerebrovascular (ACV) no fatal, necesidad de revascularizacion miocárdica (CRM) internación por angina inestable $(\mathrm{Al})$.

\section{Conclusiones}

El tratamiento con $20 \mathrm{mg}$ de rosuvastatina durante al menos 18 meses de seguimiento, mostró reducción de eventos CV mayores en pacientes con riesgo CV moderado con elevación de la PCR y bajo colesterol LDL.

Palabras claves: proteina $C$ reactiva, infarto, muerte, estatinas. Key words: $C$ reactive protein, infarct, death, statins. Fuente de financiamiento: Astrazeneca.

\section{Comentario}

Otros estudios habían documentado que la elevación de la $\mathrm{PCR}$ se asocia a mayor riesgo CV -aún en aquellos pacientes con LDL baja- $y$ también se había demostrado que el tratamiento con estatinas logra bajar la $\mathrm{PCR}^{1,2}$

En el que hoy comentamos se observó que en pacientes de 60 a 70 años de riesgo CV moderado $(40 \%$ con síndrome metabólico) pero con elevación de la PCR de alta sensibilidad -que no es la más difundida en nuestro medio- el tratamiento con $20 \mathrm{mg}$ de rosuvastatina reduce en un $46 \%$ los eventos CV mayores. Cabe destacar que se midieron objetivos duros (IAM, ACV y muerte) y que los mismos resultados se observaron en la evaluación de los subgrupos, lo que ofrece consistencia a los resultados del estudio. Sería necesario tratar 31 pacientes durante cuatro años (NNT) para evitar un evento adicional, y si bien podría considerarse que el tratamiento con estatinas reduce tanto la PCR como el LDL, se trató de una muestra de pacientes con LDL basal baja; lo que conduce a adjudicarle la mayor parte del merito a la reducción de la PCR.

\section{Conclusiones del comentador}

Podríamos considerar la medición de PCR de alta sensibilidad en pacientes con riesgo CV moderado y LDL en valores aceptables para su riesgo $\mathrm{CV}^{3}$.

Pablo Tesolin [ Coordinador de la Unidad de Ensayos Clínicos del Servicio de Medicina Familiar y Comunitaria del Hospital Italiano. pablo.tesolín@ hospitalitaliano.org.ar ]

Tesolín P. La rosuvastatina previene eventos cardiovasculares en personas con elevación de la proteina C reactiva. Evid Act Pract Ambul. 12(1): 11. Ene-Mar, 2009. Comentado de Ridker $\mathbf{P}$ y col. Rosuvastatin to prevent vascular events in men and women with elevated C-reactive protein N Engl J Med. 2008 Nov 20; 359(21):2195-207. PMID: 18997196. Disponible en URL: http://content.nejm.org/cgi/content/full/NEJMoa0807646

\section{Referencia}

1. Albert M y col. Effect of statin therapy on C-reactive protein levels: the Pravastatin Inflamatory-CRP Evaluation (PRINCE) a randomized trial and cohort study. JAMA 2001, 268:64-70.

2. Ridker $\mathrm{P}$ y col. Relative efficacy of atorvastatin $80 \mathrm{mg}$ and pravastatin $40 \mathrm{mg}$ in achieving the dual goals of low-density lipoprotein cholesterol $<70 \mathrm{mg} / \mathrm{dl}$ and $\mathrm{C}$-reactive protein <2mg/l:an analysis of the PROVE IT. J Am Coll Cariol 2005;45:1644-8.

3. National Cholesterol Education Program Adult Treatment Panel III guidelines, Circulation 2004;110:227-39/763. 